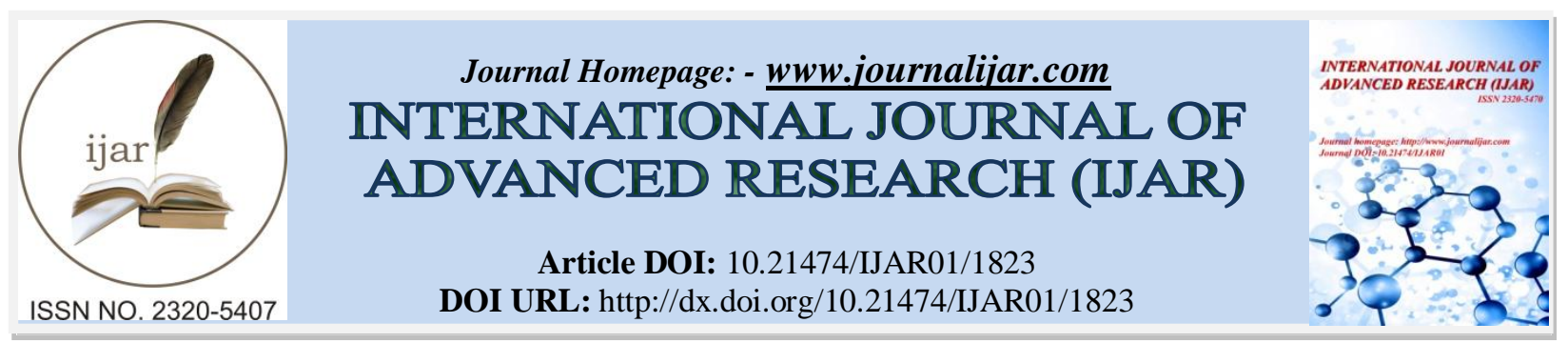

RESEARCH ARTICLE

\title{
NEW SPECIES OF DIPLOTRIAENA YUSUFI N. SP. (NEMATODE: FILARIIDAE) FROM COMMON MYNA (ACRIDOTHERES TRISTIS) LINNAEUS; 1776 (PASSERIFORMES: STURNIDAE) IN DISTRICT LARKANA, SINDH, PAKISTAN.
}

*Bakhtawar Soomro, G. S Ghachal and Naeem Narejo.

Department of Zoology, University of Sindh, Jamshoro.

\section{Manuscript Info}

\section{Manuscript History}

Received: 12 August 2016

Final Accepted: 13 September 2016

Published: October 2016

Key words:

Avian nematode, Diplotriaena yusufi $\mathrm{n}$.

sp. Common myna Acridotheres tristis,

Sindh, Pakistan.

\section{Abstract:}

A new nematode $D$. yusufi n. sp. is recorded from the body cavity of Common myna Acridotheres tristis of District Larkana, Sindh, Pakistan. In all, 35 nematodes ( $\left.\delta^{\wedge}\right)$ were recorded. Present nematodes reflect diversification from their congeners in the following charaters viz: body measurement, morphological shape, shape of tridents, shape of spicules and caudal papillae. On the basis of such morpho-metrical changes in this species; D. yusufi treated as a new species. This new species is dedicated in the honor of one of the renowned Best Biologist Prof: Dr. S. M Yusuf Shaikh.

Copy Right, IJAR, 2016,. All rights reserved.

\section{Introduction:}

The Common myna (Acridotheres tristis), sometimes spelled as mynah, and also sometimes known as "Indian myna" ${ }^{[1]}$ belonging to the Class Aves, Order Passeriformes and Family Sturnidae. It is resident of Asia. Being omnivorous in feeding habits, it is found in open wood land bird with a strong territorial instinct, and has adapted to urban environments.

The range of the Common myna is increasing at such a rapid rate that in 2000 the IUCN Species Survival Commission acknowledged it one of the world's most invasive species and one of only three birds in the top 100 species that pose an impact to biodiversity, agriculture and human interests. ${ }^{[2]}$

\section{Materials and method:}

During the present studies a total of 70 Common mynas (Acridotheres tristis) Linnaeus, 1776 were collected from different localities of Larkana District, Sindh, Pakistan and brought to the Parasitological Laboratory Department of Zoology. After anesthetizing, the birds were autopsied and examined for the helminthes parasites. During examination 35 (ठ) specimens were obtained from the body cavity of the hosts belonging to the Genus Diplotriaena Railliet and Henry, 1909. Live specimens were killed in hot $70 \%$ ethanol, cleared in lacto phenol and glycerol solution and preserved in alcohol- glycerol solution. Diagrams were made with the help of camera Lucida Garcia and Ash ${ }^{[3]}$. Photographs were taken with the help of camera DP12. Measurements were given in millimeters (mm). Specimens were deposited in the Department of Zoology, University of Sindh Jamshoro. 


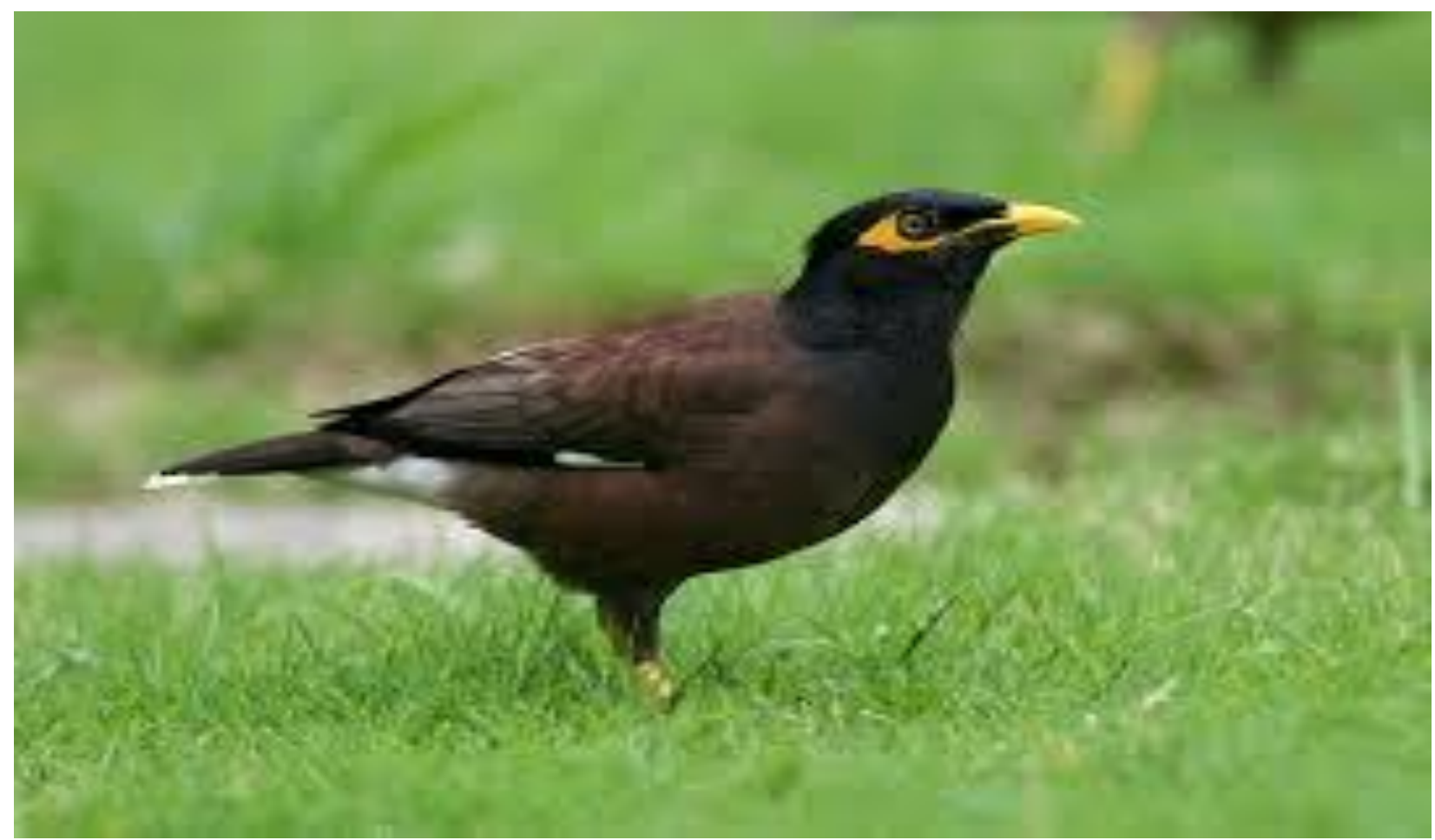

Fig 1: Photographic view of Common myna Acridotheres tristis.

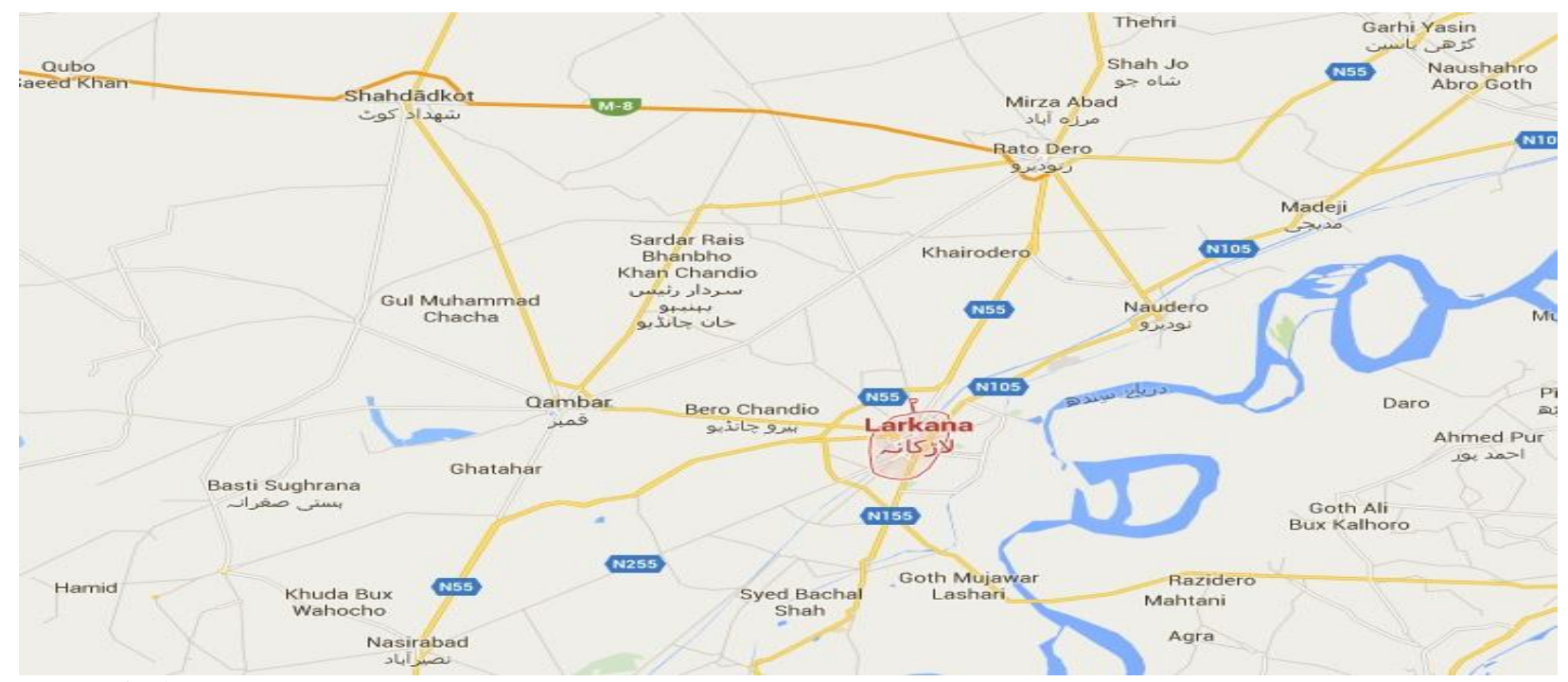

Fig 2: Map of District Larkana from where collection Common mynas Acridotheres tristis were made. 


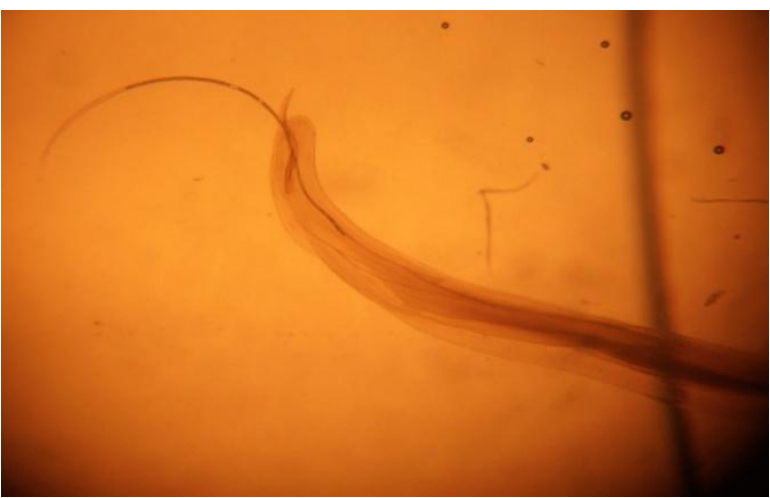

Fig: 3

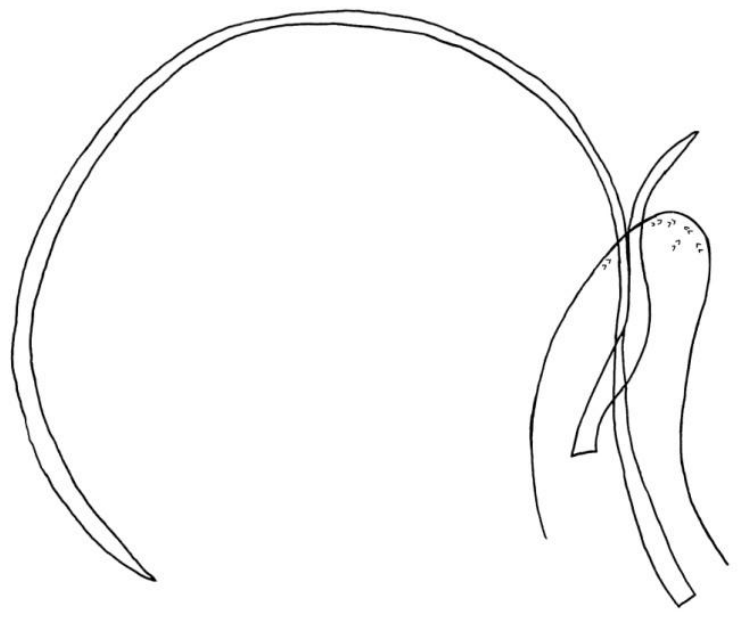

Fig: 4

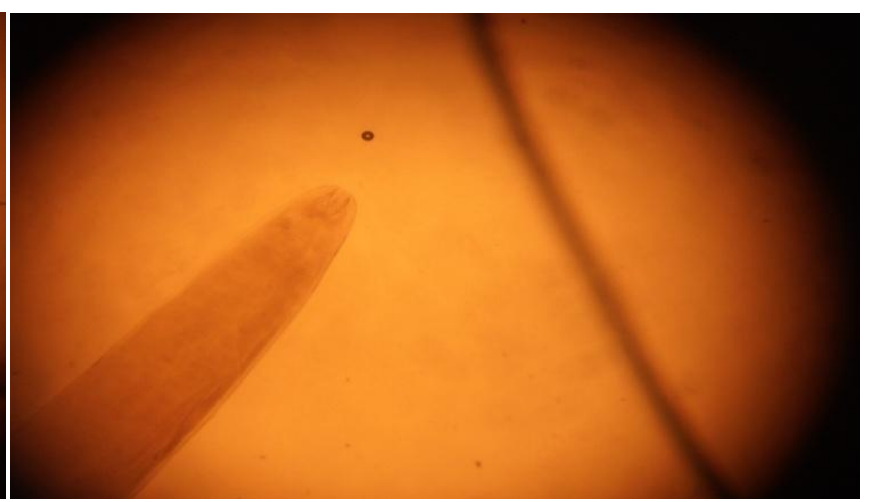

Fig: 3.1

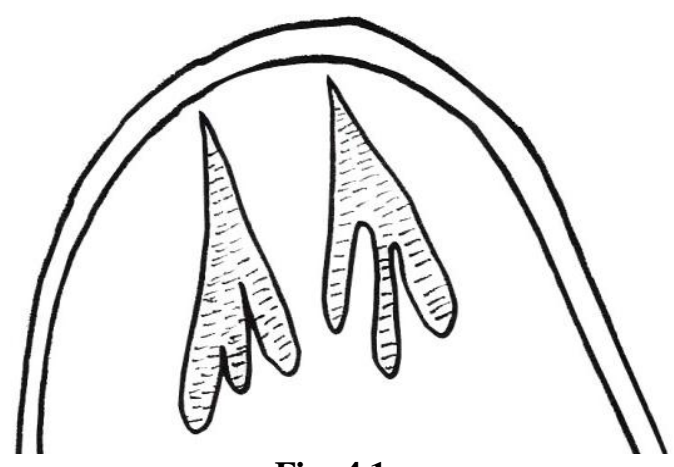

Fig: 4.1

Fig 3: Posterior photographic view of nematode n. sp.

Fig 3.1: Anterior photographic view of nematode n. sp.

Fig 4: Posterior view of nematode n. sp. Having scale bar $0.2 \mathrm{~mm}$.

Fig 4.1: Anterior view of nematode n. sp. Having scale bar $0.2 \mathrm{~mm}$.

Table 1: Comparative characteristics of various species of Genus Diplotriaena Railliet and Henry, 1909 collected from different avian hosts.

\begin{tabular}{|c|c|c|c|c|c|c|}
\hline $\begin{array}{c}\text { S.N } \\
\text { O }\end{array}$ & Parameters & Present species & D. almoraensis & D. niltavae & D. bargusinica & D. tristisi \\
\hline 1. & Body length & $\mathbf{4 0 . 2 1}$ & $\mathbf{3 9 . 2}$ & $\mathbf{2 4 . 0 - 2 4 . 4}$ & $\mathbf{3 1 . 0 - 4 6 . 4}$ & $\mathbf{3 2 . 9 4}$ \\
\hline 2. & Body width & $\mathbf{0 . 3 9}$ & $\mathbf{0 . 3 2}$ & $\mathbf{0 . 4 9 6 - 0 . 5 1 2}$ & $\mathbf{0 . 7 2 - 0 . 7 7}$ & $\mathbf{0 . 4 5 5}$ \\
\hline 3. & Tridents & $\begin{array}{c}\mathbf{0 . 1 0 - 0 . 0 7 x 0 . 1 1 -} \\
\mathbf{0 . 0 7}\end{array}$ & $\mathbf{0 . 1 6}$ & $\mathbf{0 . 1 2 8 - 0 . 1 4 4}$ & $\mathbf{0 . 1 3 - 0 . 1 4}$ & $\mathbf{0 . 1 3}$ \\
\hline 4. & $\begin{array}{c}\text { Caudal } \\
\text { papillae }\end{array}$ & $\mathbf{6}$ & $\mathbf{5}$ & $\mathbf{1 2}$ & $\mathbf{1}$ & $\mathbf{9}$ \\
\hline 5. & Left spicule & $\mathbf{1 . 5 9}$ & $\mathbf{0 . 8 4 - 1 . 0 7}$ & $\mathbf{0 . 6 5 6 - 0 . 7 2 0}$ & $\mathbf{0 . 6 4 - 0 . 6 6}$ & $\mathbf{2 . 3 9}$ \\
\hline 6. & Right spicule & $\mathbf{0 . 3 7}$ & $\mathbf{0 . 4 4 - 0 . 5 6}$ & $\mathbf{0 . 4 6 - 0 . 4 9}$ & $\mathbf{0 . 3 8 - 0 . 5}$ & $\mathbf{0 . 5 8}$ \\
\hline 7. & Host & $\begin{array}{c}\text { Acridotheres } \\
\text { tristis }\end{array}$ & Parus major & $\begin{array}{c}\text { Niltava } \\
\text { grandis }\end{array}$ & Turdus roficollis & $\begin{array}{c}\text { Acridotheres } \\
\text { tristis }\end{array}$ \\
\hline 8. & Habitat & $\begin{array}{c}\text { Body cavity } \\
\text { District } \\
\text { Larkana, } \\
\text { Pakistan }\end{array}$ & Body cavity & Body cavity & Body cavity & Body cavity \\
\hline 9. & Locality & & Bttarakhand & Bhutan & Burdwan \\
\hline
\end{tabular}


ND=not detectable

Measurement of parameters is in millimeters (Table: 1)

Results: 1

Host: Common myna

Parasitic Habitat: Body cavity

Locality: District Larkana, Sindh, Pakistan

No: of host examined: 70

No: of host infected: 25

No: of specimen recovered: 35

Etymology: The name of new species refers in the honor of one of the renowned Best Biologist Prof: Dr. S. M Yusuf Shaikh.

Systematic account:

Super family: Diplotriaenoidea

Family: Diplotriaenidae (Skrjabin, 1916)

Subfamily: Diplotriaeninae (Skrjabin, 1916)

Genus: Diplotriaena (Railliet and Henry, 1909)

\section{Description:}

Body of the worm highly muscular, thick elongated and anterio- posteriorly rounded measuring $0.21-0.44 \times 0.26$ $0.45 \mathrm{~mm}$. Both spicules protruded in opposite direction in which left large spicule measuring $1.59 \mathrm{~mm}$, and right small spicule measuring $0.37 \mathrm{~mm}$. Two tridents are similar in size, shape and the tips of the tridents are pointed measuring 0.10-0.07 x 0.11-0.07 $\mathrm{mm}$ respectively.

\section{Discussion:}

Few species of Genus Diplotriaena Railliet and Henry, 1909 have been reported worldwide; D. sternopastori, D. tristisi and D. molpastisi Majumdar and Chakravorty $1963^{[4]}$; D. chapwatensis, D. zootherae, D. niltavae and D. almoraensis S. R Dysarkar and Debabrata Sen $2008^{[5]}$; D. hamatospiculum and D. bargusinica T. D. Soota and Y. Chaturvedi $1972{ }^{[6]} ;$ D. nagpurensis, D. tricuspis, D. bhamoensis, D. graculi, D. dubia and D. urocissae H. A Baylis $1939^{[7]}$ respectively.

D. sternopastori Majumdar and Chakravorty, ${ }^{[4]}$ recorded in Sturnus contra of Burden differs from D. yusufi in having body length smaller; width narrow; trident longer; left spicule smaller; right spicule longer and 13 pairs of caudal papillae.

D. tristisi Majumdar and Chakravorty, ${ }^{[4]}$ recorded in Acridotheres tristi of Burden differs from D. yusufi in having body length smaller; width narrow; trident longer; left spicule smaller; right spicule larger and 9 pairs of sessile caudal papillae.

D. molpastisi Majumdar and Chakravorty, ${ }^{[4]}$ recorded in Acridotheres ginginianus of Burden differs from D. yusufi in having body length smaller; width narrow; trident longer; left spicule smaller; right spicule larger and 10 pairs of sessile caudal papillae.

D. chapwatensis S. R Dysarkar and Debabrata Sen, ${ }^{[5]}$ recorded in Myiophoneus caeruleus temmincki of India differs from D. yusufi in having body length smaller; width narrow; trident longer; left spicule smaller; right spicule smaller; cloaca sub terminal and 8 pairs of caudal papillae.

D. zootherae S. R Dysarkar and Debabrata Sen, ${ }^{[5]}$ recorded in Zoothra citrine citrine of Uttarakhand, differs from D. yusufi in having body length smaller; width narrow; trident longer; left spicule longer; right spicule smaller; cloaca sub terminal and 7 pairs of caudal papillae.

D. niltavae S. R Dysarkar and Debabrata Sen, ${ }^{[5]}$ recorded in Niltava grandis grandis of Uttarakhand, India differs from $D$. yusufi in having body length smaller; width maximum; trident longer with rounded tips; left spicule larger; right spicule smaller; cloaca subterminal and 12 pairs of caudal papillae. 
D. almoraensis S. R Dysarkar and Debabrata Sen, ${ }^{[5]}$ recorded in Parus major of Uttarakhand, differs from D. yusufi in having body length smaller; width narrow; trident longer; left spicule smaller; right spicule larger and 5 pairs of caudal papillae.

D. hamatospiculum T. D. Soota and Y. Chaturvedi, ${ }^{[6]}$ recorded in Turdus ruficollis of Bhutan differs from D. yusufi in having body length longer; width maximum and only 2 papillae at post anal clearly discernible.

D. bargusinica T. D. Soota and Y. Chaturvedi, ${ }^{[6]}$ recorded in Turdus ruficollis of Bhutan differs from D. yusufi in having body length smaller; width maximum; trident longer; left spicule longer; right spicule smaller and 4 pairs of caudal papillae.

D. nagpurensis H. A Baylis, ${ }^{[7]}$ recorded in Acridotheres tristis of Nagpur differ from D. yusufi in having smaller body length but maximum width; tridents longer; no caudal papillae were seen; left spicule measures larger and right spicule smaller.

D. tricuspis H. A Baylis, ${ }^{[7]}$ recorded in Acridotheres tristis of Nagpur differ from D. yusufi in having body length smaller; maximum width; tridents longer; 9-11 pairs of caudal papillae; left spicule larger and right spicule also larger.

D. bhamoensis H.A Baylis, ${ }^{[7]}$ recorded in Acridotheres tristis of Burma differ from D. yusufi in having smaller body length; left spicule smaller and right spicule also smaller.

D. graculi H. A Baylis, ${ }^{[7]}$ recorded in Pyrrhocorax of Calcutta differ from D. yusufi in having smaller body length; maximum width; tridents longer; left spicule smaller and right spicule larger.

D. dubia H. A Baylis, ${ }^{[7]}$ recorded in Pyrrhocorax of Calcutta differ from D. yusufi in having smaller body length; maximum width; left spicule smaller and right spicule larger.

D. urocissae H. A Baylis, ${ }^{[7]}$ recorded in Urocissa flavirostris of Calcuta differ from D. yusufi in having smaller body length; maximum width; tridents longer; left spicule smaller and right spicule larger.

\section{Conclusion:}

Present recorded species reflect disparity from their allies in the following characters viz: body measurement; morphological shape; shape of trident; shape of spicules and caudal papillae On the basis of such morpho-metrical changes this species; D. yusufi treated as a new species.

\section{Bibliography:}

1. Http://www.yimag.org.au/indian-myna-identification. Html.

2. Lowe S. Browne M. Boudjelas S. and de Poorter M. (2000, update 2004). 100 of the world's invasive Alien species. A selection from the Global Invasive Species Database. The Invasive Species Specialist Group (ISSP), a specialist group of the species survival commission (SSC) of the Conservation (Union IUCN), Auckland.

3. Garcia L. A. and Ash L. R. Diagnostic Parasitology: Clinical Laboratory Manual, the CV Mosby Company. 11830 West line Industrial Drive, St. Louis, Missouri 63141.7, 1979.

4. Majumdar and Chakravorty, taxonomy of the parasites, Burden, 1963; 1-26.

5. Dysarkar S. R and Debabrata Sen. On four new nematodes species of the Genus Diplotriaena Railliet and Henry, 1909, from Uttarakhand, India, Zoological survey of India, 2008; 108(4): 105-112.

6. Soota T. D and Chaturvedi Y. Systematic studies on some more nematodes from the unarmed collections of the zoological survey of India, zoological survey of India, 1972, 67: 121-137.

7. Baylis H. A. The fauna of British India, Nematoda, British Museum, 1939, 2: 36-42. 